\title{
Thermo-Stamping Process of Glass and Carbon-Fibre Reinforced Polymer Composites
}

\author{
Walid Harizi1 ${ }^{1}$ Zoheir Aboura1, Mylène Deléglise-Lagardère ${ }^{2,3}$, Valérie Briand ${ }^{4}$ \\ ${ }^{1}$ Département Ingénierie Mécanique, Laboratoire Roberval FRE UTC-CNRS 2012, Université de Technologie de Compiègne, \\ Compiègne, France \\ ${ }^{2}$ Polymers and Composites Technology \& Mechanical Engineering Department, IMT Lille Douai, Douai, France \\ ${ }^{3}$ Université de Lille, Lille, France \\ ${ }^{4}$ Zodiac Aerosafety Systems, Zodiac Elastomer Europe, Caudebec Les Elbeuf, France \\ Email: walid.harizi@utc.fr
}

How to cite this paper: Harizi, W., Aboura, Z., Deléglise-Lagardère, M. and Briand, V. (2020) Thermo-Stamping Process of Glass and Carbon-Fibre Reinforced Polymer Composites. Materials Sciences and Applications, 11, 319-337.

https://doi.org/10.4236/msa.2020.115022

Received: March 5, 2020

Accepted: May 24, 2020

Published: May 27, 2020

Copyright $\odot 2020$ by author(s) and Scientific Research Publishing Inc. This work is licensed under the Creative Commons Attribution International License (CC BY 4.0).

http://creativecommons.org/licenses/by/4.0/

(c) (i) Open Access

\begin{abstract}
In this work, manufacturing tools for thermoplastic (TP) composites have been developed. The chosen process involves the stacking alternately of oriented dry fabrics and TP films and does not use semi-products in order to reduce material costs. This study was specifically directed towards optimizing the impregnation of continuous glass and carbon fibres reinforcing two TP amorphous matrices, the polyphenylsulfone (PPSU) and polyetherimide (PEI), to obtain semi-finished products employed for aeronautical structures. The impregnation quality of inter and intra-yarns is analyzed and validated by optical and scanning micrographic observations conducted with an optical and a Scanning Electron Microscopies (SEM), respectively. The study showed that besides the process parameters and porosity distribution in the core of warp yarns, the impregnation quality depends on the surface properties of constituents. Desizing treatment has been carried out to improve the wettability of fibres by the TP matrices.
\end{abstract}

\section{Keywords}

Thermoplastic Resin, Carbon-Fibre Reinforced Polymer (CFRP), Glass-Fibre-Reinforced Polymer (GFRP), Porosity, Scanning Electron Microscopy (SEM)

\section{Introduction}

Despite the widespread use of thermosetting resins (TS) in composites for aeronautic applications over the past four decades, their processing shows some drawbacks such as the low storage temperature, long curing cycles and irreversi- 
ble process [1]. Thermoplastic (TP) composites with high-performance matrices (Polyphenylene Sulfide (PPS), polyphenylsulfone (PPSU), polyetherimide (PEI), polyetheretherketone (PEEK), etc.) can be a promising alternative to these issues. The advantages of TP composites, especially carbon-fibre reinforced polymer (CFRP) and glass-fibre reinforced polymer (GFRP), include a healthier manufacturing environment, good impact properties, reduced production cycle time as well as their easier recyclability when compared to TS composites [2] [3] [4] [5]. Crystallization of TP polymers is an important factor due to its strong influence on the mechanical and chemical properties: the crystal phase increases the stiffness and tensile strength, while the amorphous phase absorbs the impact energy [1] [6] [7]. The crystallinity degree is determined by many factors, including the polymer type and the processing conditions. Investigations of a wide range of semi-crystalline polymers show that the crystalline morphology of the thermoplastic matrix in the composite depends on the molding temperature, the residence time during melting and the cooling rate. For this reason, the consolidation process of a continuous fibrous reinforcement by an amorphous TP polymer matrix is complicated [8]. However, TP composites become attractive in the aeronautical field due to some technical properties such as increased toughness and inherent flame retardancy, as well as reduced cost processing by employing manufacturing processes like thermoforming, stamping, welding and co-consolidation [6]. As the curing phase required for TS matrices is replaced by a controlled and fast cooling phase, large-scale productions are then possible even if the manufacturing temperatures are generally higher than those of TS [8]-[13]. Several aircraft parts can be manufactured from stamped TP composites reinforced with woven continuous-carbon fibres such as ribs and spars of engine nacelles [6]. From one manufacturer to another, the mechanical and physical characteristics may change in large proportions affected by the manufacturing method. Furthermore, the high viscosity of TP polymers makes the impregnation of reinforcement more difficult compared to TS matrices [8]-[13]. Consequently, some semi-products have emerged to overcome this drawback but with a restricted number of suppliers. The forming process of continuous fiber-reinforced thermoplastic is generally conducted at the melting temperature of the thermoplastic resin. In this case, the resin can be considered as liquid, and the processing parameters including the maximum applied pressure, compaction rate, and consolidation time must be evaluated [8]-[13]. Polymer melt viscosity is a crucial property used for plastics processing. Its dependency on strain rate is primary knowledge for successful adjustment of fabrication conditions. Besides temperature and pressure conditions are the other manufacturing variables affecting polymer viscosity. For pressure, it is complicated to evaluate its influence; for this, it is usually omitted. This can be accepted for "low-pressure" technologies, as for example, casting, but not for injection molding or extrusion, where pressures up to $100 \mathrm{MPa}$ or $40 \mathrm{MPa}$, respectively [14].

Internal stresses generated during the cooling phase and residual porosities after molding are important issues for TP laminate composites. They are asso- 
ciated with the difference in thermal expansion of their components, the organization of those ingredients, and the processing history of the material. In a unidirectional (UD) composite, the thermal expansion of the fibres is nearly zero while that of the matrix phase is large. When the composite is cooled from its processing temperature, the matrix tries to shrink but is prevented by the stiff inextensible fibres, which leads the resin and the fibres under tensile and compressive stress, respectively [15] [16]. In addition to these phenomena, the lay-up sequence must be stacked symmetrically to the neutral plane so as to not introduce residual stresses in the composites. Although there are large volume changes between the melting point and the glass transition temperature $(T g)$, three-quarters of the total stress is generated between $T g$ and ambient temperature during the cooling phase [17]. Internal stresses contribute directly to the performance of the composite structure by defects introduction such as microcracking initiation and delamination under mechanical loading [18]-[23].

The development of autonomous means for the design and manufacture of TP composite structures would be a vital strategic asset, especially for the transport industries. For this, this study focuses on the implementation of composites with continuous woven fibres and TP matrices. It is mainly directed towards impregnation optimization of the reinforcements (glass and carbon fibres) by two high-performance amorphous TP matrices (PPSU and PEI), to obtain semi-finished products that can be used directly for the forming of aircraft parts. The choice of two amorphous matrices is related to the end application of the composite materials developed in this study that will be used for an aeronautical structure subjected to the impact and hydraulic crash loadings. GFRP and CFRP plates with an average thickness of $3 \mathrm{~mm}$ are implemented using a thermo-stamping process proposed under vacuum with an optimized porosity level.

The originality of this study lies in the proposal of a new innovative experimental protocol for the rapid manufacture of TP composite plates. The porosity rate of the developed materials will be evaluated by a simple determination of the material density, while the impregnation quality of the fibrous reinforcement by the two TP matrices (PPSU and PEI) will be checked by micrographic inspections carried out in the thickness of TP specimens.

In the next sections of this paper, the viscosity investigation of the two TP matrices will be briefly presented followed by a discussion of the proposed method that will be used to evaluate the porosity rate. Thermo-stamping parameters process will be experimentally investigated and the residual porosities will be evaluated. The study is completed with optical and scanning micrographics obtained from the through-thickness analysis of several specimens at different locations of the manufactured TP plates.

\section{Theoretical Background}

\subsection{The Viscosity of TP Polymers}

TP polymers exhibit great potential for recycling due to their reversible process. However, their significant viscosity makes the impregnation of the dry rein- 
forcements more difficult when compared to TS composites [1]-[14] [24] [25]. Viscosity varies as a function of shear rate $\dot{\gamma}$, commonly represented by the power-law proposed for the first time by Ostwald in 1925. An extension of the power-law is the flow relationship of Carreau which is written as a function of shear rate $\dot{\gamma}$, temperature $T$ and pressure $p$ [24]. To evaluate the viscosity of TP at high temperatures by simultaneously varying shear rate $\dot{\gamma}$, temperature $T$ and pressure $p$, Sedlacek et al. have developed a rheometer with a backpressure device (a capillary rheometer Göttfert) to generate backpressure and thereby to raise the pressure in the polymer melting process. Temperature and pressure dependencies of the shear viscosity were recorded via measurements in temperature and pressure regions covering the regular processing conditions of PPSU. The acquired flow curves were fitted according to the Carreau-Yasuda model, and therefore, temperature and pressure effects on viscosity behavior were evaluated [14]. Figure 1 illustrates the results obtained at different pressures and strain rates. As indicated at $345^{\circ} \mathrm{C}$ and ambient pressure, the viscosity of PPSU is 1116 Pa.s. The same value is also found for the PEI at $370^{\circ} \mathrm{C}$ [25]. It confirms the complexity of the fibrous reinforcement impregnation by these TP matrices during the consolidation process. Nevertheless, under a low strain rate, two parameters $(T, p)$ have presented essential contributions for an optimum consolidation of TP plates.

\subsection{Porosity Evaluation}

Generally, many methods can be employed for porosity evaluation. However, only a few such as microtomography [26] [27], ultrasound [28] [29] [30], chemical degradation [31] and image analysis [32] [33] [34] [35] [36] can be used to quantify the voids or closed gaps which are inaccessible by external agents (for e.g., mercury, nitrogen, argon). The microtomography is a recent $3 \mathrm{D}$ nondestructive technique, providing a volume image from the distribution of the linear absorption coefficient $(\mu)$ of the X-ray. Since the materials do not have the same $\mathrm{X}$-ray absorption coefficients, it is possible to obtain a 3D mapping of the TP fibrous composite [26]. It is then easy to calculate the volume fraction of these gaps inside the material, but also to analyze their morphology, distribution, etc. However, this technique is relatively expensive and applicable to a minimal volume, not necessarily representative of the part, particularly due to the very large amount of the generated data per sample.

Chemical degradation (or burn-out test) involves heating the sample at high temperature to cause combustion of the polymer matrix. The major issue of this procedure lies mainly in the evaluation of the density of composite material by hydrostatic weighing (a Mohr weighing scale according to standard NF EN ISO 1183). It may alter the density measurements due to the nature of composite materials that generally present porosities and, therefore, allow the liquid diffusion into their voids.

For reasons as mentioned above, the present study proposes evaluating the porosity using the following method: 


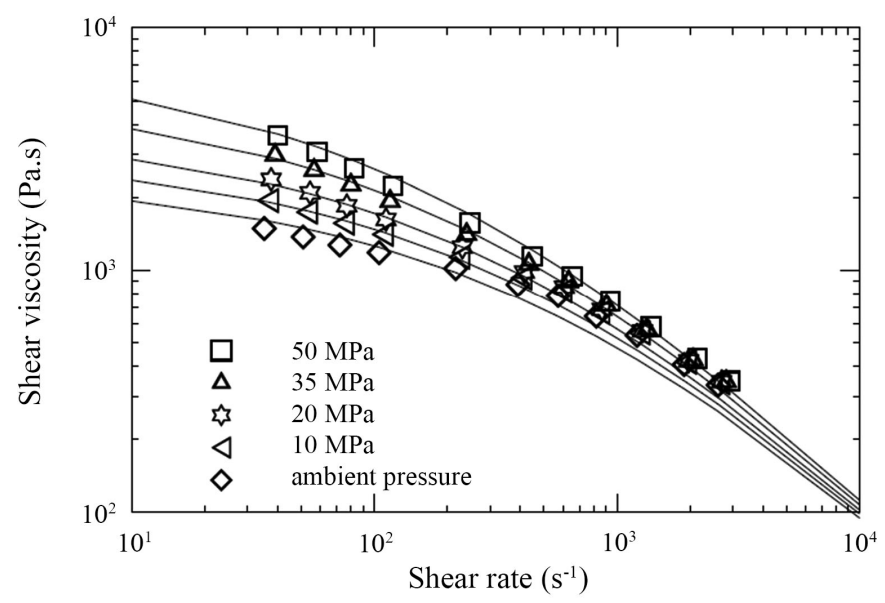

Figure 1. Shear viscosity versus shear rate of PPSU conducted at $345^{\circ} \mathrm{C}$ and different pressures [14].

The total volume percentage $(100 \%)$ is the sum of the volume fraction of the fibres $V_{f}$ and matrix $V_{m}$ while adding their volume porosity ratio $V_{p}$ (Equation (1)).

$$
V_{p}+V_{f}+V_{m}=1 \Leftrightarrow V_{p}=1-\left(V_{f}+V_{m}\right)
$$

Knowing that $v_{f}=m_{f} / \rho_{f}$ is the volume of fibres and $v_{m}=m_{m} / \rho_{m}$ is the volume of the matrix, we can rewrite the Equation (1) as seen in Equation (2):

$$
V_{p}=1-\frac{v_{f}+v_{m}}{v_{p}+v_{m}+v_{f}}=1-\frac{\frac{m_{f}}{\rho_{f}}+\frac{m_{m}}{\rho_{m}}}{\frac{m_{f}+m_{m}}{\rho}}
$$

The volume fraction of porosity $V_{p}$ can be determined by Equation (3) with the mass ratio of the fibers $M_{f}=1 / 1+\frac{\rho_{m}}{\rho_{f}}\left(\frac{1}{V_{f}}-1\right)$ and matrix $M_{m}=1-M_{f}$ :

$$
V_{p}=1-\rho\left[\left(\frac{m_{f}}{m_{f}+m_{m}}\right) \frac{1}{\rho_{f}}+\left(\frac{m_{m}}{m_{f}+m_{m}}\right) \frac{1}{\rho_{m}}\right]=1-\rho\left[\frac{M_{f}}{\rho_{f}}+\frac{M_{m}}{\rho_{m}}\right]
$$

where $\rho, \rho_{f}$ and $\rho_{m}$ are the densities of composite, fibres and matrix, respectively. Fibres volume fraction, $V_{f}$ is given by Equation (4) where $N$ is the number of plies, $A_{s}$ is the fabric area weight $\left(\mathrm{g} / \mathrm{m}^{2}\right)$ and $h$ is the sample thickness.

$$
V_{f}=\frac{N A_{s}}{\rho_{f} h}
$$

The CFRP and GFRP specimens are cut by water jet with their dimensions (length ${ }^{\star}$ width $^{\star}$ thickness) as an average of three measurements carried out at different locations for each edge by a digital micrometer (accuracy $\pm 2 \mu \mathrm{m}$ ), and their weights are measured by an electronic balance at high resolution $\left(10^{-4} \mathrm{~g}\right)$. The ratio of mass to volume results in the density $\rho$. 


\section{Experimental Study and Results}

The materials employed for the manufacturing of the composite plates are presented in this section. They consist of two types of TP matrices, PPSU and PEI, and two $2 / 2$ twill weave fabrics, made from glass and carbon fibres. Also, the experimental protocol to obtain the composite plates is described.

\subsection{Materials}

\subsubsection{Amorphous TP Matrices}

Ultem 1000-1000 natural PEI (amber) is a high-performance engineering thermoplastic polymer, displaying high strength and modulus combined with good processability. It is presented in film form with a thickness of $125 \mu \mathrm{m}$. Its characteristics are similar to those of PEEK. However, it has a lower cost. PEI has a tensile modulus $E$ of $3.1 \mathrm{GPa}$ and a density $\rho_{P E I}=1.27 \mathrm{~g} / \mathrm{cm}^{3}$. It is reported by the manufacturing company (Ajedium Films, Solvay) to have high heat resistance, being able to withstand long-term exposure at elevated temperatures with excellent thermal stability. Otherwise, as an amorphous polymer, it is usually processed at temperatures sufficiently higher than its glass transition temperature $\left(215^{\circ} \mathrm{C}\right)$. The reported processing temperatures of PEI are between $340^{\circ} \mathrm{C}$ and $400^{\circ} \mathrm{C}$.

Radel R5000 PPSU natural film (clear) is an amorphous, high-performance thermoplastic polymer offering high heat distortion temperature, outstanding mechanical properties over a wide temperature range (better impact resistance than polysulfone or PEI), also at very low temperatures, extraordinary hydrolysis, and chemical resistance when compared to other amorphous thermoplastics. It is supplied by "Ajedium films" society in the form of sheets having a thickness of $125 \mu \mathrm{m}$. PPSU has a modulus $E=2.35 \mathrm{GPa}$, a glass transition temperature $T g$ $=220^{\circ} \mathrm{C}$ and a density $\rho_{P P S U}=1.29 \mathrm{~g} / \mathrm{cm}^{3}$. PPSU needs high manufacturing temperatures (stiff macromolecules of PPSU need to be machined above $330^{\circ} \mathrm{C}$ ), e.g., preferred melt temperature during injection moulding is usually in the range of $335^{\circ} \mathrm{C}-400^{\circ} \mathrm{C}$. Thus, PPSU is often used for medical, automotive and aerospace applications.

\subsubsection{Fabrics}

In this study, the two types of $2 / 2$ twill fabrics are supplied by "Porcher Composites-France", made with E-glass fibres and $3 \mathrm{~K}$ carbon fibers, respectively. Table 1 summarizes their references and characteristics. The density of E-glass fibre is $\rho_{E-\text { Glass }}=2.54 \mathrm{~g} / \mathrm{cm}^{3}$ with a diameter $\phi_{E}=9 \mu \mathrm{m}$. The total number of filaments in the warp of glass fabric is 2112 filaments. For the $3 \mathrm{~K}$ carbon yarn (with 200 tex), the warp and the weft of carbon fabric are composed of 3000 filaments. Knowing the density of $3 \mathrm{~K}$ carbon fibre $\rho_{3 K}=1.76 \mathrm{~g} / \mathrm{cm}^{3}$, the diameter of carbon filament can be evaluated $\phi_{3 K}=7 \mu \mathrm{m}$. The weight of $3 \mathrm{~K}$ carbon fabric is 285 $\mathrm{g} / \mathrm{m}^{2}$, whereas it is $399 \mathrm{~g} / \mathrm{m}^{2}$ for the E-glass. This allows us to have two fabrics with the same equivalent volume of reinforcements $\left(162 \mathrm{~cm}^{3} / \mathrm{m}^{2}\right.$ for carbon $\mathrm{fa}$ bric and $157 \mathrm{~cm}^{3} / \mathrm{m}^{2}$ for glass one). In the representation of the weave pattern in 
Table 1. Characteristics of the yarns used in the manufacturing of the two $2 / 2$ twill fabrics.

\begin{tabular}{|c|c|c|c|c|c|c|c|c|c|}
\hline \multirow{2}{*}{ Product } & \multicolumn{2}{|c|}{ Yarn type } & \multirow{2}{*}{$\begin{array}{l}\text { Weight } \\
\left(\mathrm{g} / \mathrm{m}^{2}\right)\end{array}$} & \multirow[b]{2}{*}{ Weave Pattern } & \multirow{2}{*}{ Sizing } & \multicolumn{2}{|c|}{ Nominal texture } & \multicolumn{2}{|c|}{ Mass distribution } \\
\hline & Warp & Weft & & & & $\begin{array}{c}\text { Warp } \\
(\text { yarn/cm) }\end{array}$ & $\begin{array}{c}\text { Weft } \\
\text { (counts/cm) }\end{array}$ & Warp & Weft \\
\hline $\begin{array}{c}3 \mathrm{~K} \\
\text { carbon fabric }\end{array}$ & $\begin{array}{c}\text { Tenax } \\
\text { HTA } \\
5131 \\
(200 \text { tex })\end{array}$ & $\begin{array}{c}\text { Tenax } \\
\text { HTA } \\
5131 \\
(200 \text { tex })\end{array}$ & 285 & & - & 7.0 & 7.0 & $50 \%$ & $50 \%$ \\
\hline $\begin{array}{l}\text { E glass } \\
\text { fabric }\end{array}$ & $\begin{array}{c}\text { EC9 } \\
68 \times 5 \\
\text { t0 } \\
(340 \text { tex })\end{array}$ & $\begin{array}{l}\text { EC9 } \\
273\end{array}$ & 399 & & - & 6.0 & 6.6 & $53 \%$ & $47 \%$ \\
\hline
\end{tabular}

column 5 of Table 1, warp yarns are shown by a black color, whereas white color is attributed to weft yarns. During the manufacturing fibres, they are surface-treated with an aqueous solution. This treatment of the fibre surfaces is called sizing. Sizing influences the properties of the interface between fibres and their matrix, and subsequently affects the mechanical properties of composites. It is known that sizing is effective for TS matrices, but far from being mastered for TP matrices. Although several studies were conducted investigations on the evaluation of sizing chemical formulation applied to glass and carbon fibres, it remains highly industrial and confidential (noted “-” in Table 1). The yarns are equilibrated in warp and weft directions for the $3 \mathrm{~K}$ carbon and E-glass $2 / 2$ twill fabrics (Table 1).

\subsection{Proposed Thermo-Stamping Process}

The manufacturing processes of TP plates with continuous fibers are still homemade, and everyone has its expertise depending on the targeted applications. The process used in this study was optimized to obtain flat plates with parallel faces, uniform thickness, and good impregnation quality. To meet these requirements, the chosen manufacturing method was the compression molding process by thermo-stamping. It is performed using a rapid stamping press of "COGIT Composites-France" society, which exerts a maximum closing pressure $\mathrm{P}_{\max }$ between two heating trays. The CFRP and GFRP plates should have a thickness of $3 \mathrm{~mm}$ and a fibre volume fraction of $40 \%$. According to Equation (4), the required number of plies is evaluated to 8 . To avoid internal residual stresses, the stacking must be symmetrically related to the middle of the thickness. So, 16 TP films were intercalated symmetrically between the 8 dry plies in fibrous reinforcement. The used experimental setup is shown in Figure 2: the stacking (16 sheets and 8 plies, Figure $2(a))$ is placed under vacuum $(-0.9$ bar), 
the used polyimide vacuum bag has a thickness of $75 \mu \mathrm{m}$ and withstands temperature of $450^{\circ} \mathrm{C}$. A square metal frame with $3 \mathrm{~mm}$ in thickness is placed around the stacking outside the vacuum bag. The set is placed in the press (Figure 2(b)) which is previously heated to a $\mathrm{T}_{0}$ temperature at its two upper and lower platens. Stamping occurs by compaction of the stacking by upper platen displacement, while the lower platen is held fixed. During the compression process, the vacuum is maintained in order to evacuate the air trapped within the stacking, ensuring a low rate of voids in the composite plate at the end of the manufacturing cycle. The metal frame is used to set the final thickness of TP plates $(3 \mathrm{~mm})$. A groove in one of its sides was machined to establish the link between the vacuum hose and the stacking, through a strip of glass mat. Impregnation quality depends on the material constituents, resin viscosity, and fabric permeability. The viscosity of TP resin depends essentially on three parameters, shear rate $\dot{\gamma}$, pressure $p$ and temperature $T$. As slow displacements are applied during the thermo-stamping process, shear rates are low and viscosity can be considered constant during the isothermal process cycle. During the compaction operation, the material is compressed, implying an increase in the fibre volume fraction and a decrease in the fabric permeability. Therefore, a study of process parameters ( $p, T$, time) is necessary to study the impregnation quality.

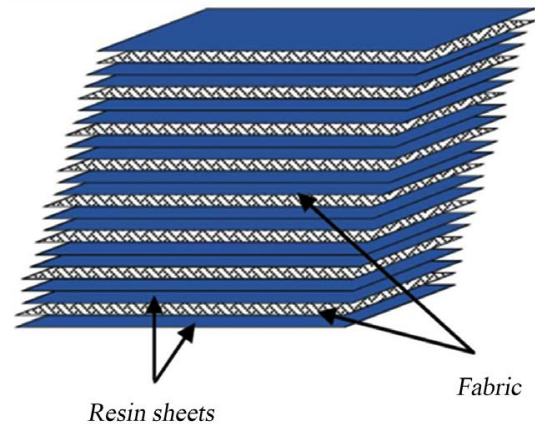

(a)

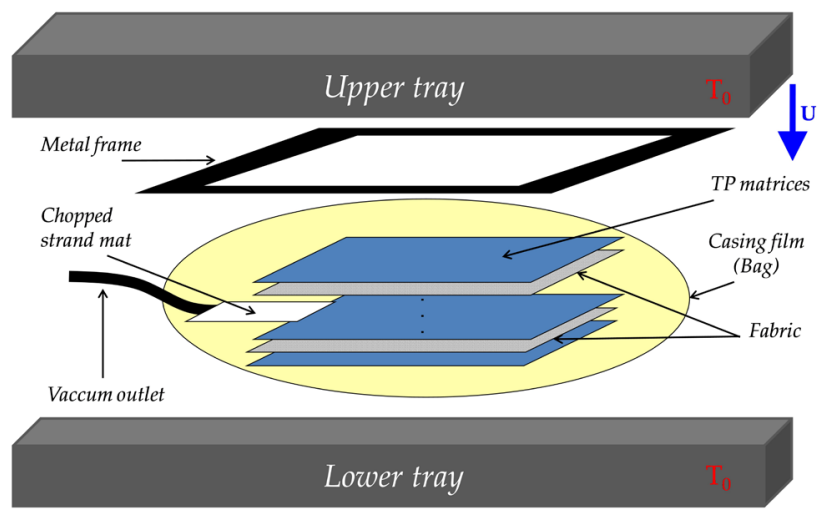

(b)

Figure 2. Stacking sequence (a), schematic representation of the experimental setup (b). 


\subsubsection{Compaction Cycle Parameters}

Three different cycles were applied to the two TP polymers PPSU and PEI reinforced with glass and carbon fibres. In the first (Figure 3(a)), $p$ is maintained at $17 \%$ of $\mathrm{P}_{\max }$ for 14 minutes and reaches the maximum pressure during the last minute of cycle 1 . The processing temperature is $\mathrm{T}_{0}=355^{\circ} \mathrm{C}$. During the second and third cycles (Figure 3(b) and Figure 3(c)), the compression time is increased compared to cycle 1 , and four pressure levels are prescribed (8 minutes at $17 \%, 8$ minutes at $52 \%, 8$ minutes at $87 \%$ and 1 minute at $100 \%$ of $\mathrm{P}_{\max }$ ). The only difference between cycles 2 and 3 is the transformation temperature which reaches $\mathrm{T}_{0}=365^{\circ} \mathrm{C}$ in the third cycle. $\mathrm{P}_{\max }$ during the last minute ensures that the upper tray sits on the metal frame in the cycle ends, so it guarantees the final thickness $(3 \mathrm{~mm})$ of TP composite plates. The choice of a short heat-stamping time of 14 minutes for the first cycle and 25 minutes for cycles 2 and 3 is essential because the consolidation process must be fast enough for an industrial rate.

Figure 4 shows pictures of typical TP composite plates obtained respectively by the three cycles. Plate 1 (Figure 4(a)) shows horizontal black lines and some transparent areas between these lines, which are less apparent on plate 2 (Figure 4(b)). Plate 3 presents a degradation of the TP resin (Figure 4(c)). The various areas on plate 1 reflect poor and heterogeneous impregnation of reinforcement by its TP resin. This defect is mainly due to the abrupt transition of pressure from $17 \%$ to $100 \%$ of $\mathrm{P}_{\max }$. A stepwise increase in the pressure prevents this defect (Figure $4(\mathrm{~b})$ ). On the other side, a temperature increase of $10^{\circ} \mathrm{C}$ has an adverse effect on plate 3 . Thus the transformation temperature of $355^{\circ} \mathrm{C}$ is considered the most suitable to obtain a melt PPSU and PEI.

Optical micrographs are conducted on the thickness of samples cut from the three plates. Figure 5(a) is the result of the fusion of the micrographic observations using the free ICE Microsoft software to investigate the total thickness of plate 1. Plate 1 presents inter-ply areas poorly compacted and large porosities (black spots) concentrated mainly in the warp strands. This observation can be generalized for the three TP plates, less pronounced for plate 2 in Figure 5(c) but blatant in plate 3 (Figure 5(d)) where voids (big air bubbles) come to settle even in the thermoplastic matrix. Porosities are located principally in the core of warp strands, observed in the detail enlargement shown in Figure 6 at the fiber scale $(20 \mu \mathrm{m})$. In close confirmation with micrographic observations already discussed, plate 2 presents the lowest porosity fraction with a mean value $V_{p}=$ $3 \% \pm 0.2 \%$ evaluated in Table 2 using Equation (3) from five samples cut on each TP plate. A low constant compacting pressure for 14 minutes (cycle 1) was insufficient to introduce the melted resin into the fibre strands. On the other hand, an increase of the pressure by steps (cycles 2 and 3) makes it possible to pump, step by step, the resin into the core of the strand. The abrupt increase in pressure can abruptly compress the stack, increase the fibre content, enclose the voids between the filaments of the same roving and thus prevent TP viscous resin enough to get inside the strands for to be able to coat filaments. 
(a)
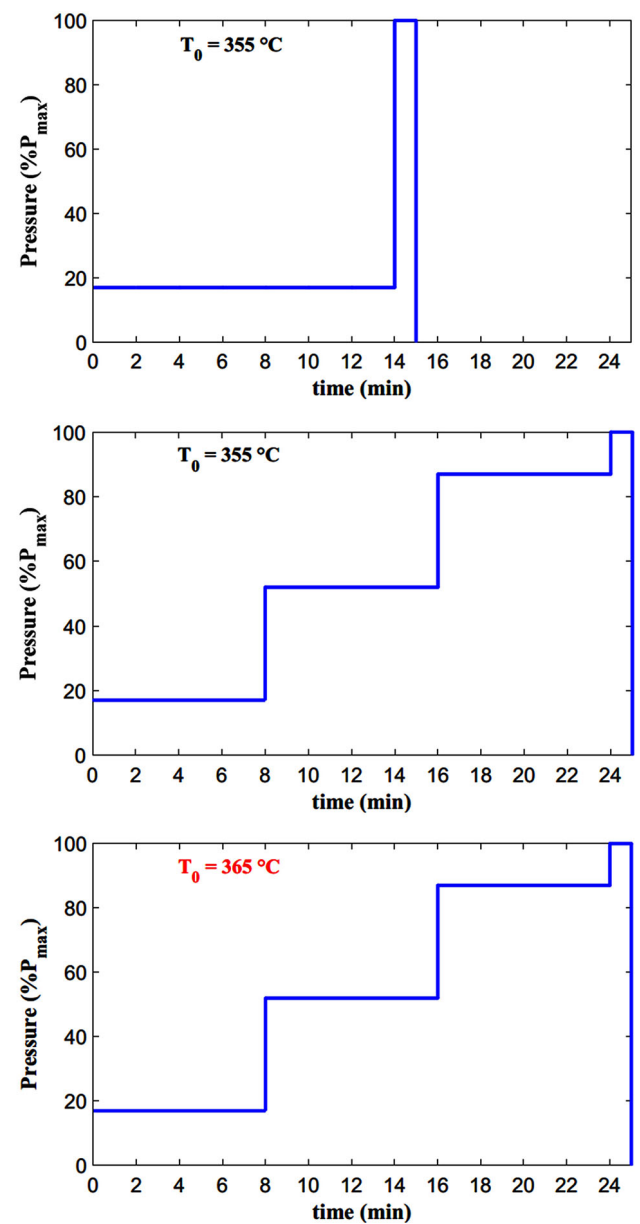

Figure 3. Three compacting cycles for the manufacture of TP composite plates: (a) the first, (b) second, and (c) third cycles.

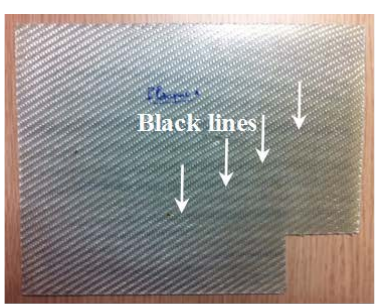

(a)

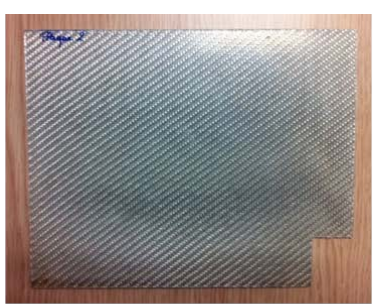

(b)



(c)

Figure 4. Typical TP plates obtained using cycle 1 (a), cycle 2 (b) and cycle 3 (c).

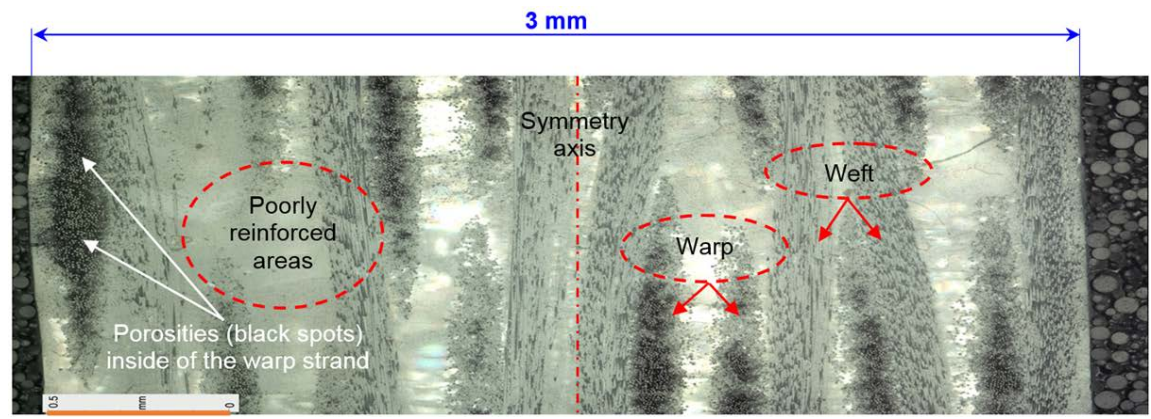

(a) 




(b)

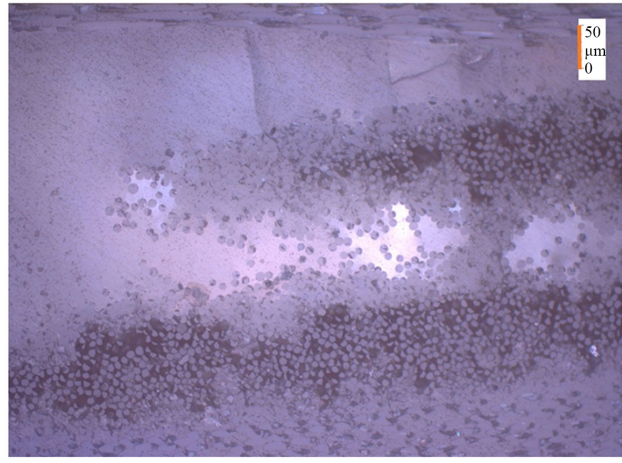

(c)

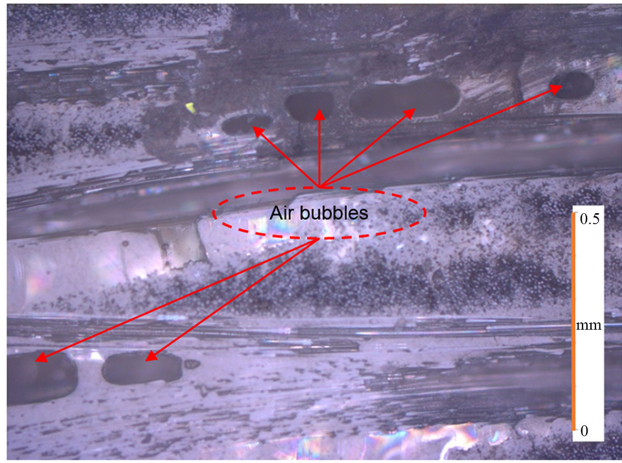

(d)

Figure 5. Optical micrographs conducted on the thickness of plate 1 (a), at the strand scale of plate 1 (b), 2 (c) and 3 (d).

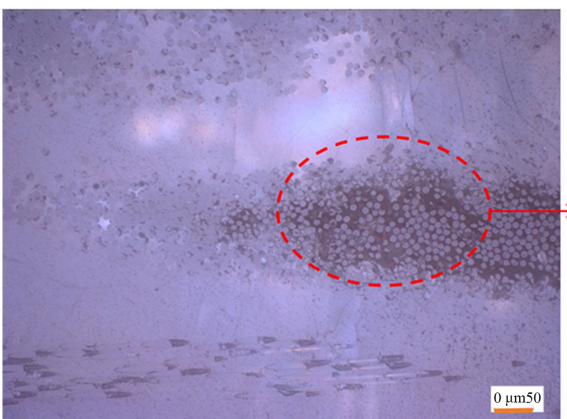

(a)



(b)

Figure 6. Porosity location in the center of warp roving. 
Table 2. Porosity evaluation of the three plates 1, 2 and 3 (mean values).

\begin{tabular}{ccc}
\hline Plate $^{\circ}$ & $\begin{array}{c}V_{p}(\%) \\
\text { [Equation (3)] }\end{array}$ & $\begin{array}{c}V_{f}(\%) \\
\text { [Equation (4)] }\end{array}$ \\
\hline 1 & $4 \pm 0.3$ & $42 \pm 0.4$ \\
2 & $3 \pm 0.2$ & $41.6 \pm 0.4$ \\
3 & $7 \pm 0.5$ & $43 \pm 0.5$ \\
\hline
\end{tabular}

So, the real challenge in thermo-stamping is the optimization of the time-pressure window at the adequate consolidation temperature: at a low strain rate and constant transformation temperature, the key parameter of the thermo-stamping process is the compaction pressure. According to the three proposed cycles, it is essential to adjust the pressure by steps so as not to suddenly close the spaces between the fibers of the same strand and therefore prevent impregnation by the capillarity phenomenon. On the other hand, the temporal pressure adjustment must not be over a very long duration (the pressure should be maintained just during a few minutes) in order to promote a reasonable industrial production.

Industrially, only warp filaments undergo sizing and porosities located essentially in warp strands let us conclude that impregnation defects are due to sizing. For this reason, we decide to continue the thermo-stamping process of TP composites by applying the same experimental protocol (cycle 2, Figure 3(b)) but while removing the sizing (desizing) of the two $2 / 2$ twill glass and carbon fibres.

\subsubsection{Effects of Desizing Treatment}

\section{a) Procedure}

The heat treatment consists of putting the dry glass and carbon fabrics before consolidation in a calcination furnace at $400^{\circ} \mathrm{C}$ for 4 hours. Unlike glass fibre, carbon can react with oxygen in the air to form $\mathrm{CO}$ or $\mathrm{CO}_{2}$ and can volatilize. For this reason, to protect it, the calcination furnace was continuously fed with industrial nitrogen during the passage of carbon fabric. A temperature of $400^{\circ} \mathrm{C}$ does not cause adverse effects on the mechanical properties of glass and carbon fibres and allows them to burn sizing. To understand the effect of this desizing treatment, SEM micrographs are conducted on two $3 \mathrm{~K} 2 / 2$ twill carbon fabric samples, the first is sized (Figure $7(\mathrm{a})$ and Figure $7(\mathrm{~b})$ ) while the second (Figure 7(c) and Figure 7(d)) is desized. These observations show that sizing, with a coating substance unevenly distributed on the fibre surface, makes more complex the impregnation of the fibre in the core of strand and disturbs the capillarity phenomenon reacting the microscopic intra-ply impregnation. A simple spreading test of a water drop on the desized fabric proves a total wettability and quite fast, which explains that the surface tension of the fiber weakens after desizing. Therefore, the proposed heat treatment increases the wettability of rein- 
forcement components of the composite material.

\section{b) Thermo-stamping tests with desized fabrics}

Figure 8(a) and Figure 8(b) show two photos of typical TP composite plates manufactured with desized glass and carbon fibres, respectively. Both were thermo-stamped according to cycle 2 with a processing temperature $\mathrm{T}_{0}=355^{\circ} \mathrm{C}$. All composite plates (with PPSU or PEI) have a mirror effect, a good surface finish, and a uniform thickness $(3.0 \pm 0.15 \mathrm{~mm})$. The average porosity fraction $V_{p}$, evaluated by Equation (3) based on five specimens cut of each plate, is $0.84 \%$ $\pm 0.13 \%$ for glass fibre plates and $3.0 \% \pm 0.6 \%$ for carbon ones. The impregnation of the 8 glass plies becomes better due to desizing treatment. This is verified from the micrographic observations conducted on the thickness of TP plate shown in Figure 8(a) where voids are almost negligible (very small black spots) over the entire thickness and the compaction quality is homogenous and better (short and homogenous intra/inter-ply distance). In contrast, with carbon fibres (Figure 8(b)), inter-strand impregnation governed by the viscous forces is satisfactory, but the intra-strand one dominated by capillary forces is bad: the presence of the porosities (black areas) in the core of weft and warp rovings. TP resin cannot reach the core of the strand. This may suggest that compaction velocity was high and viscous forces dominate the flow of melt TP resin through the thickness of the stack. If this is true we must find the same observation on the glass fabric. In fact, carbon strand consists of 3000 fibres with a diameter of 7 $\mu \mathrm{m}$, and after compaction, it forms an ellipse with a surface of $0.176 \mathrm{~mm}^{2}$ (Figure 8(b)) while glass strand is made up only with 2000 filaments which a diameter of $9 \mu \mathrm{m}$ and the area of the formed ellipse after consolidation can be measured $0.247 \mathrm{~mm}^{2}$ (Figure $8(\mathrm{a})$ ). The ratio of two surfaces is 1.4 times while the small area (that of carbon) includes more than a third of the smaller diameter fibres.

Micrographic observations conducted with SEM still show the presence of porosities inside warp yarns (Figures $9(\mathrm{a})-(\mathrm{c})$ ) and at fibres scale with a small size (Figure $9(\mathrm{~d})$ ). Thereby, the impregnation difficulty of carbon yarn is mainly due to the small diameter of filaments $(7 \mu \mathrm{m})$ and their high number that participates in the constitution of the yarn (3000 filaments/yarn). During the heat-stamping process, continuous woven fibres interlock with each other by sliding. More pressure increases, strands become deformed by decreasing their waviness amplitude, inducing a reduction in the thickness of the plies taken individually. The compaction causes a modification of the geometry of strands towards ellipsoids more and more flattened. This generates a monotonic increase in the reinforcement volume fraction, decreases the intra-strand voids, decreases the permeability of the fibrous media, and impedes TP resin too viscous to be introduced by the capillarity approach inside the quite tight strand. During the manufacturing process, the permeability of glass fabric is thus higher (more spaces between filaments), which allows easier yarn impregnation than with carbon fibres. 


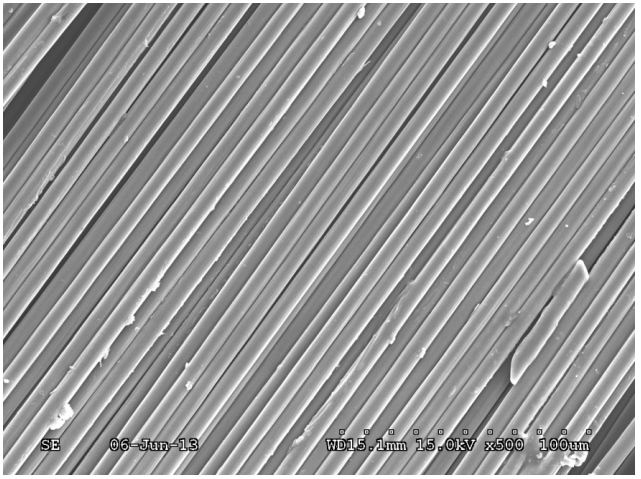

(a)

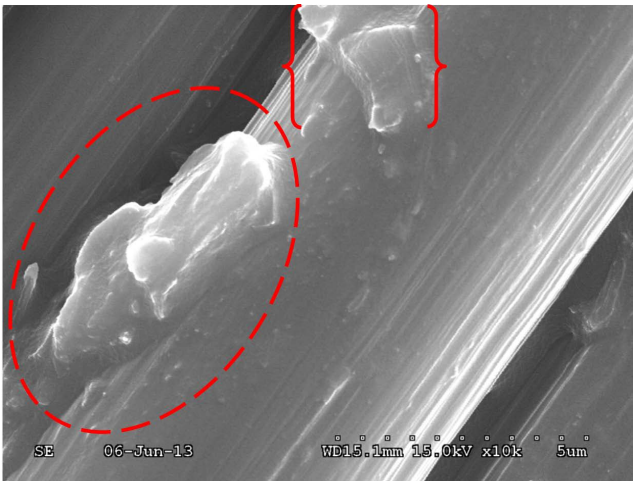

(b)

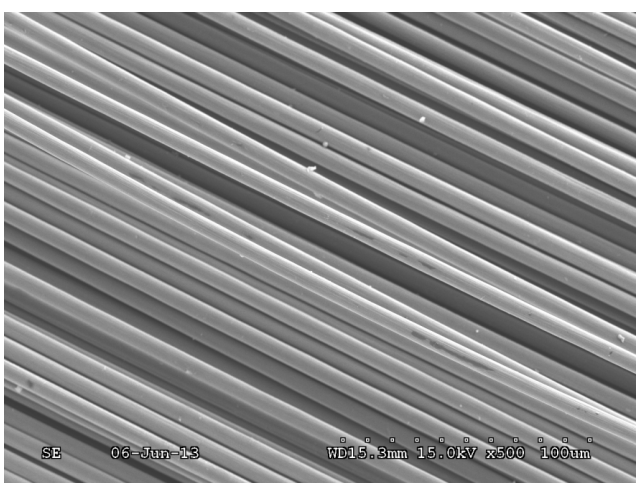

(c)

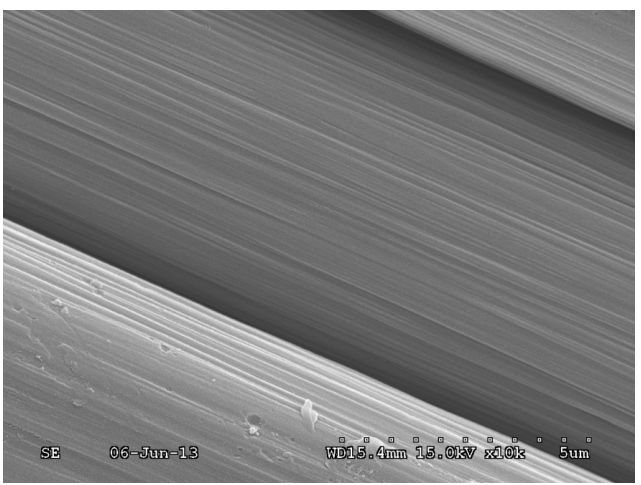

(d)

Figure 7. Effect of desizing treatment of carbon fabric: sized (a) (b) and desized fibres (c) (d). 


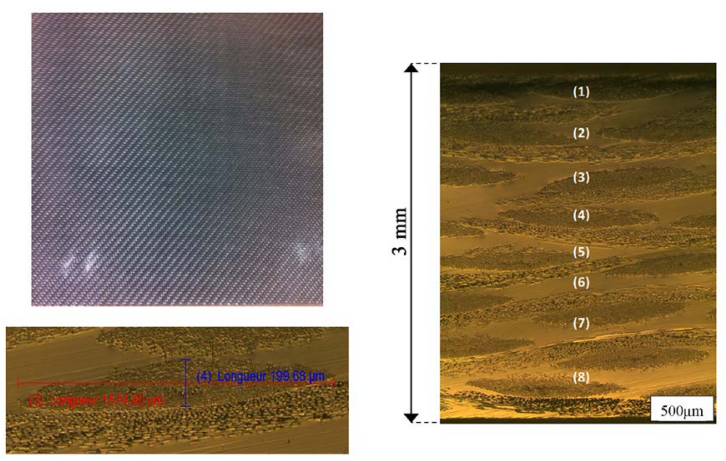

(a)
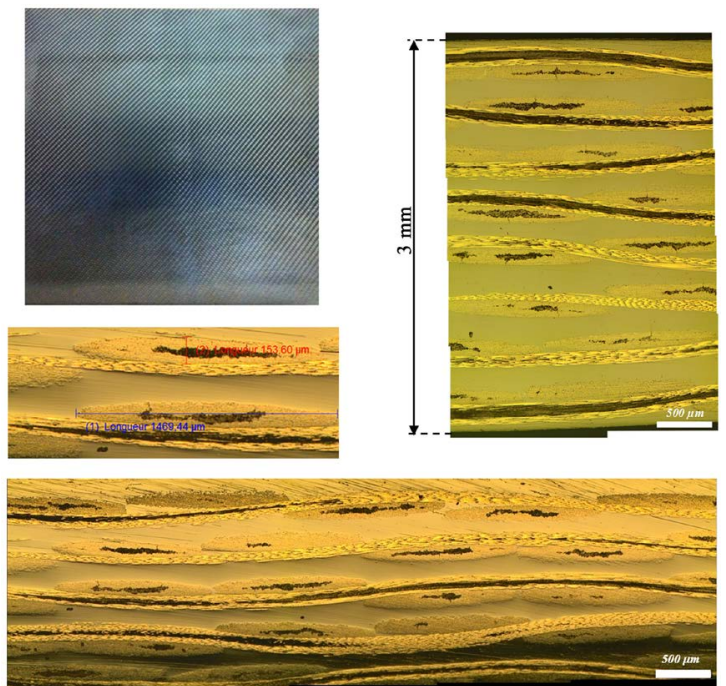

(b)

Figure 8. Micrographic observations conducted on typical TP composite plates with desized glass (a) and carbon fibres (b).

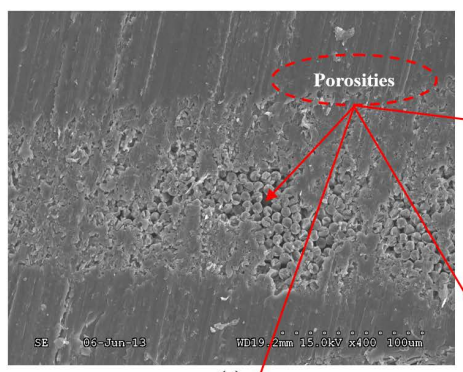

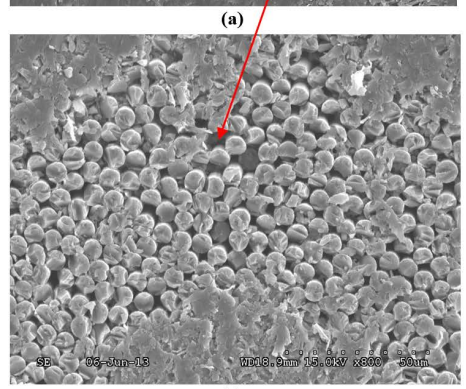

(c)
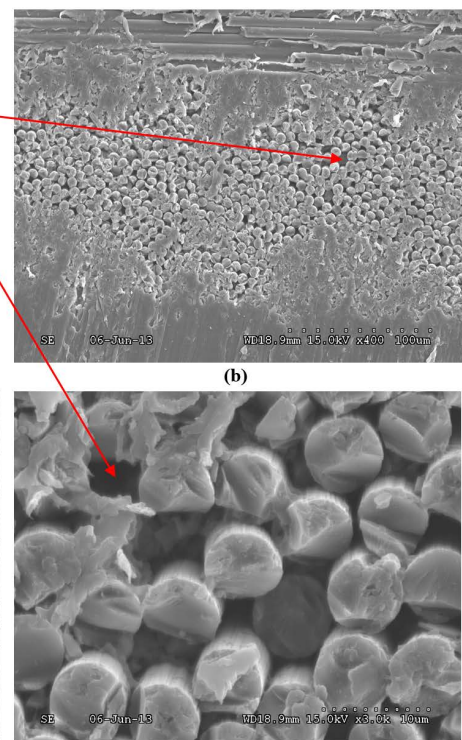

(d)

Figure 9. SEM micrographs of PPSU/carbon composite in the warp roving (a)-(c) and at fibres scale (d). 


\section{Conclusion}

In this study, a manufacturing process of TP (PPSU and PEI) composite plates reinforced with $2 / 2$ twill glass and carbon fibres was proposed using a thermo-stamping molding approach. Three stamping cycles were tested, including a working temperature, a pressure range and holding times. It was shown that the transformation temperature of $355^{\circ} \mathrm{C}$ is considered the most suitable to obtain a melt PPSU and PEI resins. Also, a stepwise increase of compacting pressure allows a better consolidation with a low porosity fraction. Similarly, an increase in the cycle duration promotes the capillarity of TP resins inside the strand. Inter/intra-ply impregnation quality was evaluated following optical and SEM micrographic observations conducted on the thickness of TP composite plates. Porosity evaluation was performed using a new simple approach based on the density evaluation of composite material. Porosity concentration was focused especially on warp yarns. For this reason, desizing of fabrics was established to decrease the surface tensions of filaments and facilitate the impregnation of glass and carbon fibres. As the structure of a fabric, yarn dimensions and shape, number of fibers per yarn and fibre diameters affect the rate at which matrix impregnation and fiber wetting occur and therefore influence the time to consolidate, the impregnation difficulty of carbon yarn is mainly due to the small diameter of filaments and their high number that participates in the constitution of the yarn. The viscous resin cannot coat 3000 filaments with a very small diameter $(7 \mu \mathrm{m})$. As the current sizing solutions are very compatible with TS matrices, the definition of the appropriate new solutions with TP matrices constitutes a very promising research challenge.

\section{Acknowledgements}

The authors would like to thank Hauts-de-France region, Normandie region and FEDER (Fonds européen de développement régional), patrons of the Project "ACCECOTP" (Amélioration du Comportement au Crash et aux Chocs des Equipements en Composites Thermo Plastiques) which financed research presented in this paper.

\section{Conflicts of Interest}

The authors declare no conflicts of interest regarding the publication of this paper.

\section{References}

[1] Spruiell, J.E. and Janke, C.J. (2004) A Review of the Measurement and Development of Crystallinity and Its Relation to Properties in Neat Poly(phenylene sulfide) and Its Fiber Reinforced Composites. Technical Report ORNL/TM-2004/304. Metals and Ceramics Division, US Department of Energy, Washington DC. https://doi.org/10.2172/885940

[2] Offringa, A.R. (1996) Thermoplastic Composites, Rapid Processing Applications. Composites: Part A, 27, 329-336. https://doi.org/10.1016/1359-835X(95)00048-7 
[3] Hou, M. (1996) Stamp Forming of Fabric-Reinforced Thermoplastic Composites. Polymer Composites, 17, 596-603. https://doi.org/10.1002/pc.10649

[4] Diaz, J. and Rubio, L. (2003) Developments to Manufacture Structural Aeronautical Parts in Carbon Fibre Reinforced Thermoplastic Materials. Journal of Materials Processing Technology, 143-144, 342-346. https://doi.org/10.1016/S0924-0136(03)00450-3

[5] Ning, H., Vaidya, U., Janowski, G.M. and Husman, G. (2007) Design. Manufacture and Analysis of a Thermoplastic Composite Frame Structure for Mass Transit. Composite Structures, 80, 105-116. https://doi.org/10.1016/j.compstruct.2006.04.036

[6] Vieille, B., Albouy, W., Chevalier, L. and Taleb, L. (2013) About the Influence of Stamping on Thermoplastic-Based Composites for Aeronautical Applications. Composites: Part B, 45, 821-834. https://doi.org/10.1016/j.compositesb.2012.07.047

[7] Vieille, B., Casado, V.M. and Bouvet, C. (2014) Influence of Matrix Toughness and Ductility on the Compression After-Impact Behavior of Woven-Ply Thermoplasticand Thermosetting-Composites: A Comparative Study. Composite Structures, 110 , 207-218. https://doi.org/10.1016/j.compstruct.2013.12.008

[8] Denault, J. and Dumouchel, M. (1998) Consolidation Process of PEEK/Carbon Composite for Aerospace Applications. Advanced Performance Materials, 5, 83-96. https://doi.org/10.1023/A:1008638105370

[9] Cogswell, F.N. (1991) The Experience of Thermoplastic Structural Composites during Processing. Composites Manufacturing, 2, 208-216.

https://doi.org/10.1016/0956-7143(91)90142-4

[10] Wang, C. and Sun, C.T. (1997) Experimental Characterization of Constitutive Models for PEEK Thermoplastic Composite at Heating Stage during Forming. Journal of Composite Materials, 31, 1480-1506. https://doi.org/10.1177/002199839703101502

[11] Hwang, S.F. and Hwang, K.J. (2002) Stamp Forming of Locally Heated Thermoplastic Composites. Composites Part A: Applied Science and Manufacturing, 33, 669-676. https://doi.org/10.1016/S1359-835X(02)00004-0

[12] Van West, B.P., Pipes, R.B. and Advani, S.G. (1991) The Consolidation of Commingled Thermoplastic Fabrics. Polymer Composites, 12, 417-427. https://doi.org/10.1002/pc.750120607

[13] Chen, Q., Boisse, P., Park, C.H., Saouab, A. and Bréard, J. (2011) Intra/Inter-Ply Shear Behaviors of Continuous Fiber Reinforced Thermoplastic Composites in Thermoforming Processes. Composite Structures, 93, 1692-1703. https://doi.org/10.1016/j.compstruct.2011.01.002

[14] Sedlacek, T., Hausnerova, B. and Filip, P. (2012) Viscosity Measurements of Polyphenylsulfone Melt. In: Recent Researches in Environmental and Geological Sciences, WSEAS Press, Athens, 429-431.

[15] Manson, J.A. and Seferis, J.C. (1987) Internal Stress Determination by Process Simulated Laminates' SPE. 45th Annual Technical Conference and Exhibition, Los Angeles, 4-7 May 1987, 1446-1449.

[16] Chapman, T.J., Gillespie Jr., J.W., Pipes, R.B., Manson, J.A.E. and Seferis, J.C. (1990) Prediction of Process-Induced Residual Stresses in Thermoplastic Composites. Journal of Composite Materials, 24, 616-643. https://doi.org/10.1177/002199839002400603

[17] Jeronimidis, G. and Parkyn, A.T. (1988) Residual Stresses in Carbon Fibre Ther- 
moplastic Matrix Laminates. Journal of Composite Materials, 22, 401-415. https://doi.org/10.1177/002199838802200502

[18] Hahn, H.T. and Pagano, N.J. (1975) Curing Stresses in Composite Laminates. Journal of Composite Materials, 9, 91-106. https://doi.org/10.1177/002199837500900110

[19] Weitsman, Y. (1979) Residual Thermal Stresses Due to Cool-Down of Epoxy-Resin Composites. Journal of Applied Mechanics, 46, 563-567. https://doi.org/10.1115/1.3424606

[20] Hahn, H.T. (1976) Residual Stresses in Polymer Matrix Composite Laminates. Journal of Composite Materials, 10, 266-278. https://doi.org/10.1177/002199837601000401

[21] Tseng, S.-C. and Osswald, T.A. (1994) Prediction of Shrinkage and Warpage of Fiber Reinforced Thermoset Composite Parts. Journal of Reinforced Plastics and Composites, 13, 698-720. https://doi.org/10.1177/073168449401300803

[22] Hsiao, S.-W. and Kikuchi, N. (1999) Numerical Analysis and Optimal Design of Composite Thermoforming Process. Computer Methods in Applied Mechanics and Engineering, 177, 1-3. https://doi.org/10.1016/S0045-7825(98)00273-4

[23] Berthelot, J.M. (1992) Matériaux Composites-Comportement mécanique et analyse des structures. Masson, Paris.

[24] Carreau, P.J., De Kee, D.C.R. and Chabra, P.R. (1997) Rheology of Polymeric Systems: Principles and Applications. Munich, New York.

[25] Frigione, M., Naddeo, C. and Acierno, D. (1996) The Rheological Behavior of Polyetheretherketone (PEEK)/Polyetherimide (PEI) Blends. Journal of Polymer Engineering, 16, 217-229. https://doi.org/10.1515/POLYENG.1996.16.3.217

[26] Schell, J.S.U., Renggli, M., van Lenthe, G.H., Müller, R. and Ermanni, P. (2006) Micro-Computed Tomography Determination of Glass Fibre Reinforced Polymer Meso-Structure. Composites Science and Technology, 66, 2016-2022. https://doi.org/10.1016/j.compscitech.2006.01.003

[27] Madra, A., El Hajj, N. and Benzeggagh, M. (2014) X-Ray Microtomography Applications for Quantitative and Qualitative Analysis of Porosity in Woven Glass Fiber Reinforced Thermoplastic. Composites Science and Technology, 95, 50-58. https://doi.org/10.1016/j.compscitech.2014.02.009

[28] Mascaro, B. (2006) Caractérisation ultrasonore de la porosité dans les composites. $\mathrm{PhD}$ Thesis, UPS, Toulouse, 170.

[29] Harizi, W., Chaki, S., Bourse, G. and Ourak, M. (2012) Characterization of the Damage Mechanisms in Polymer Composite Materials by Ultrasonic Waves, Acoustic Emission and Infrared Thermography. 15th European Conference on Composite Material, Venice, 24-28 June 2012, 24-28.

[30] Harizi, W., Chaki, S., Bourse, G. and Ourak, M. (2015) Mechanical Damage Characterization of Glass Fiber-Reinforced Polymer Laminates by Ultrasonic Maps. Composites Part B: Engineering, 70, 131-137. https://doi.org/10.1016/j.compositesb.2014.11.014

[31] Ledru, Y., Piquet, R., Michel, L., Schmidt, F. and Berhnart, G. (2009) Quantification 2-D et 3-D de la porosité par analyse d'images dans les matériaux composites stratifiés aéronautiques. Proceeding of Comptes Rendus des JNC 16, Toulouse, June 2009, hal-00386035, $11 \mathrm{p}$.

[32] Purslow, D. (1984) On the Optical Assessment of the Void Content in Composite Materials. Composites, 15, 207-210. https://doi.org/10.1016/0010-4361(84)90276-3 
[33] Russ, J.C. and Dehoff, R.T. (1986) Practical Stereology. 2nd Edition, Plenum Press, New York. https://doi.org/10.1007/978-1-4899-3533-5

[34] Aliotti, A. (1996) Caractérisation microstructurale des céramiques par analyse d'images. Spectra Analyse, 188, 34-37.

[35] Redon, C., Chermant, L., Quenec'h, J.L. and Chermant, J.L. (1997) Caractérisation par analyse d'images de la morphologie de bétons renforcés par des fibres de fonte amorphe. Annales du bâtiment et des travaux publics, 4, 37-53.

[36] Shen, H., Oppenheimer, S.M., Dunand, D.C. and Brinson, L.C. (2006) Numerical Modeling of Pore Size and Distribution in Foamed Titanium. Mechanics of Materials, 38, 933-944. https://doi.org/10.1016/j.mechmat.2005.06.027 